\title{
Social systems intervention and crisis resolution. Part 2: Intervention
}

\author{
Christopher Bridgett \& Paul Polak
}

Abstract Home treatment as an alternative to acute adult in-patient care is part of the National Health Service's Plan for mental health services in the UK. As a form of crisis intervention, it benefits from an understanding of, and ways of working with, the social systems relevant to the patient in crisis. This article describes the social systems intervention process as an alternative to admission and also considers its application in achieving early in-patient discharge.

This is the second part of a two-part article. Part 1 (Bridgett $\mathcal{E}$ Polak, 2003, this issue) introduced the context for this overview, covering terminology and theory, social factors and admission to an acute psychiatric ward, crisis assessment and practical problemsolving, and the preliminary social systems assessment.

\section{The first social system meeting: continuing the assessment}

With the completion of early information gathering, it becomes possible to arrange a social system meeting with the patient (Fish, 1971; Polak, 1971, 1972). Such meetings can be seen as an opportunity for gathering further information, and for 'natural group' work or therapy. It is recommended that two members of staff facilitate each meeting, perhaps with one more active than the other. Time should be spent discussing the meeting beforehand, and afterwards, with an account written up for future reference.

A backlog of unexpressed emotion can cause tension in the first meeting, making it especially potent (Fish, 1971). It is an important opportunity for face-to-face confrontation. The sooner it occurs, the better, as passage of time can allow a crisis to ' $g o$ off the boil' or can cause the situation to become entrenched and more difficult to unravel. The venue of the meeting is not always important, but a 'natural' rather than a formal setting helps to set the scene. It might be useful to have the meeting in a setting relevant to the social system involved (Polak, 1971; Rosen, 1997; Polak et al, 1977).
It is important that essential medical treatment for the patient is not seen as contraindication for a meeting. Although oversedation should be avoided, meetings are entirely compatible with (and, arguably, enhanced by) appropriate medication (Fish, 1971).

There are several factors to take into account for a successful social system meeting (Boxes 1-3). The choice of those to be present and the patient's consent are clearly important. Those who are present will partly dictate what can be said at the meeting. The emphasis should be on the 'here and now'. The approach should be collaborative, 'doing with' rather than 'doing to'. Participants are encouraged to find their own solutions and to make their own decisions (Rosen, 1997). At the beginning of the meeting the crisis resolution team representatives should establish how long the meeting will last: its duration can be flexible, if all agree - flexibility and informality improve communication. If any
Box 1 The first social system meeting
Arrange the meeting as soon as possible Involve all relevant people
Have it in a 'real-life' situation
Clarify the limits and expectations
Explore the 'here and now'
Do 'with', rather than 'to'
Go as far and as fast as the system allows
Back off at any resistance

Christopher Bridgett is the consultant psychiatrist with the South Kensington and Chelsea Crisis Resolution Team, London, and honorary clinical senior lecturer at Imperial College School of Medicine, London (Central and North West London NHS Trust, South Kensington and Chelsea Mental Health Centre, 1 Nightingale Place, London SW10 9NG, UK. E-mail: christopher.bridgett@nhs.net). Paul Polak is the president and founder of International Development Enterprises, Lakewood, Colorado, USA, and was the executive director and founder of Southwest Denver Community Mental Health Services, Denver, Colorado. 


\section{Box 2 Facilitating social system meetings}

Have an initial hypothesis

Use two facilitators, one active and one passive

Promote healthy coping by:

- Confrontation of reality

- Expression of feelings

- Acceptance of help

Be flexible and allow free discussion

Encourage face-to-face confrontation

Close with each participant giving a summary of the meeting

Revise the initial hypothesis

participants need to arrive late or leave early this is best mentioned at the beginning, to avoid misunderstanding. It might be important to explain that the content of the discussion cannot be predetermined and that a second meeting might be held if it seems helpful. However, a great deal of important work can be achieved in just one meeting, if the appropriate social system has been chosen and the issues leading to the referral crisis have been correctly identified.

Before the meeting begins, the crisis resolution team should have a broad possible agenda in mind. This can be based on the hypothesised links between the system represented by the meeting, the crisis that seems to have happened and the behaviour linked with the crisis. The first purpose of the meeting is to refine these hypotheses and establish their validity. It might be necessary to develop or abandon and replace the original ideas, depending on the outcome of the meeting.

The team staff should not initially set the pace of a social system meeting. It can be allowed to develop its own rhythm and perspective, and go at its own speed. Usually this allows pertinent issues to surface as the dynamics of the system establish themselves. If any resistance is encountered, the pace can be slowed (Polak, 1971). During a meeting its duration can be renegotiated - extending a meeting can raise tension sufficiently to clarify issues by enabling discussion.

\section{Box 3 Further techniques for social system meetings}

Reflect, condense, reword

Extend to raise tension

Explore non-verbal behaviour

Interpret cautiously

Use spokespeople

Try psychodrama techniques
It is recommended that interpretations are used only cautiously, if at all. The principle of self-repair or self-healing is more important (Fish, 1971), by the promotion of natural adaptive coping through confrontation of reality, expression of feelings and acceptance of help (Caplan, 1964, 1974; Polak, 1971).

Active listening, with reflection, condensing and rewording, is recommended, as is drawing attention to discrepancies between verbal and non-verbal behaviour. What is said may be at odds with how people seem. Monitoring and feeding back covert communication may open up emotion-laden sources of conflict (Polak, 1971, 1972).

To help individuals to express their point of view, it might be useful to appoint spokespeople form the team (Polak, 1972). Acting as advocates, their natural function of speaking for an individual in a social system and thereby helping healthy coping can be invaluable in a meeting.

Special techniques used in psychodrama might be useful (Fish, 1971; Polak, 1972). For example, in 'doubling' a therapist provides a 'second voice' for someone who has difficulty in expressing their feelings. Standing behind or next to the person, the therapist might say 'I think it might help if I say for you what I think you're feeling: say if it's wrong or tell me to stop if you want me to.' The use of such methods, which can enable participation and improve the process of a meeting, depend very much on the aptitude and skill of the therapists. It is important that the approach is appropriate to the situation and is understood and accepted by the participants. Nothing should be forced.

As work proceeds, with assessment leading to intervention and crisis resolution, layers of difficulty can emerge, perhaps involving more than one social system. Underlying problems might become evident only when the presenting problem has been dealt with.

Vignette $1^{1}$
A middle-aged professional woman, living alone since
the death of her mother, presents with severe
depression, off sick from work and chronically
intoxicated with alcohol. Telephone calls establish that
the referral crisis involves longstanding close friends
and the parish priest, who are exhausted by their
efforts to support her. She has no family living nearby.
A meeting involving all concerned with the crisis
allows those present to agree an initial plan for home
treatment rather than admission to hospital. It also
clarifies that further social systems work is indicated:
difficulties at work and conflicts in the family need to

1. The illustrative case studies are based on real cases, but details have been omitted or changed to ensure that there is no breach of confidentiality. 
be addressed. It is also evident that the woman's future ability to cope will depend on her being put in good contact with alcohol misuse services.

At the end of a social system meeting, it can be useful to ask each participant to say something about the meeting, especially if some have remained relatively silent. After the meeting, it is crucial for the team members present to ensure that the main issues highlighted and worked through in the meeting are both fed back to the full team and written up, to ensure continuity between assessment and further intervention.

\section{Social systems interventions}

As with all health care, help and therapy begin with appropriate assessment, especially when the process is collaborative (Rosen, 1997). Acknowledgement that social systems exist and that social factors are relevant is often the first intervention (Box 4). 'Intervention' has a very active, practical, directive ring about it. At systems meetings what works best might be more tentative. Once the relevant people have been brought together, just understanding, explanation and suggestion might be required. Assessment contributes the next intervention: identification of the origins of the referral crisis. This intervention might need considerable discussion, on more than one occasion. However, the necessary short-term goals (Rosen, 1997) can become evident quite quickly.

\section{Vignette 2}

A refugee in a profoundly disturbed mental state is referred by his general practitioner: he has an established history of schizophrenia. The initial concern revolves around his not coping with activities of daily living: he has inadequate income, is living in a bed and breakfast hotel room and has had an apparent relapse of his mental illness despite continuing medication. When seen on his own by the team, his illness seems florid and disabling. Telephone enquiries reveal that, before his recent placement in the neighbourhood, he had established contact with a wide variety of helping agencies.

At the first and only social system meeting needed, the various involved agencies are able to agree a

\section{Box 4 Social systems interventions}

Explaining the relevance of social factors Identifying the agreed crisis origins Agreeing necessary short-term goals Agreeing possible long-term goals Enabling these changes, monitoring outcome

\section{Box 5 Short-term changes}

Coordinate involved support

Give practical advice, e.g. on benefits and housing

Negotiate extra professional support

Improve understanding and communication

Discuss possible $v$. impossible changes

coordinated plan for the immediate future. Interestingly, the patient's mental state at the meeting is transformed from that of a grossly disabled individual when seen on his own to that of an eloquent and able participant in his social support system meeting. Care coordination is soon transferred from the crisis resolution team to the community mental health team.

Vignette 2 illustrates the importance of seeing the patient as a person, how the labelling process mentioned in Part 1 (Bridgett \& Polak, 2003, this issue) can militate against this and how social context can have a profound effect on behaviour.

Social systems theory posits that a particular event in a given system might represent a reaction to an event elsewhere in the same or in a connected system: action at one point can therefore be expected to lead to a reaction elsewhere. In the same way that the individual presenting in crisis may benefit from practical help (Box 5), assessment of the immediately relevant social system might reveal that significant others in another system are also in need of such help, and providing this might enable the presenting system to return to equilibrium.

\section{Vignette 3 \\ A middle-aged woman with schizophrenia and problem use of alcohol discontinues her medical treatment, avoids contact with her community psychiatric nurse and presents in an acutely disturbed and self-neglected state. Assessment reveals that the man with whom she lives and on whom she depends has recently become concerned regarding the welfare and health of a relative. He has become less able to give support and attention to his partner. \\ New arrangements for her support set up by the crisis resolution team enable him to renegotiate a realistic relationship with her, with the possibility of helping him to deal with the difficulties of his relative.}

Thus, although assessment of social systems usually involves meeting with those involved, many important interventions can be achieved outside such meetings. Once arranged, a meeting can ensure continuing acceptance of help. This may be a care programme approach meeting (Department of Health, 2000). 
Poverty has profound impact on social systems (Belle, 1983). Vignette 4 shows that simple economic interventions can produce important social systems benefits.

\section{Vignette 4 \\ A female immigrant, who lives with her mother and who has been hearing voices for many years, is referred to the crisis resolution team with an increasingly disturbed mental state: her voices are now instructing her to behave violently towards others. She is contemplating ending her life. She has not worked for any significant period since coming to the UK with her mother and father several years earlier. The mother and father have divorced, and the mother now receives modest maintenance from her ex-husband. \\ The first social system meeting reveals that, of all the matters discussed, the patient's eligibility for UK social security benefits is for them the most important issue.}

The economic context is as important to the social system as the social system context is to the patient. Access to benefits, adequate housing and, if possible, productive work (generating improved self-esteem) will have a profound positive impact on the capacity of social systems to operate effectively.

The success of a crisis resolution team depends on its links with a mental health service of which it is only a part. The importance of support from a worker in a community mental health team for a particular patient's social system might become apparent only when that support is no longer available, as illustrated in the next vignette.

\footnotetext{
Vignette 5

A single mature student from Jamaica presents in crisis with psychotic preoccupations. It transpires she has previously been successfully treated in hospital for a paranoid reaction following the death of her daughter from cancer. Subsequently she presents in crisis again, with a similar mental state, when unable to cope with the complexities of attending college, working part-time and claiming appropriate benefits. However, her delusionary complaints resolve without medication when financial help is arranged via the community mental health team. Now, a few weeks later, at her current presentation, it transpires that with recovery from her last episode of illness follow-up support was discontinued.

The crisis resolution team successfully negotiates reallocation of a care coordinator from the community mental health team, and with this additional continuing support she once more becomes symptomfree - again without medication.
}

Most fundamental in early social system meetings is the opportunity for those present to understand and communicate important issues and perceptions, through open discussion. This process in itself can allow short-term positive changes to occur without any further intervention. Providing information, for example on what is possible and what is impossible, allows those involved to cope adaptively again, when uncertainty had provoked potentially disastrous behaviour.

\section{Vignette 6 \\ An elderly married man presents himself via his wife's general practitioner, having asserted that he is going to leave his wife and live on the streets. During the previous night he had become terrified for their safety at home, believing that they were in danger from people who were attacking them through the ventilation system. Thinking his wife already dead, he roused their neighbours and called the police and an ambulance. \\ Temporary alternative accommodation is found for him and he accepts neuroleptic medication. At the first meeting with his wife it transpires that she has just received notification to attend hospital for surgery, but the seriousness of her condition is unclear. It also becomes evident that he has become socially isolated recently, following the death of a particular friend. \\ Arrangements are made to help them better understand the prognosis of her condition - it is good - and suggestions regarding opportunities for him to meet others with similar interests are accepted enthusiastically. The day before his wife's operation he agrees to move back to their home.}

Within a social system that is in equilibrium, each member has roles and functions. Disturbances in a system caused by life events and developments such as separation, bereavement and maturation may require those surviving or remaining to renegotiate roles and functions (Box 6) for the system to reestablish its equilibrium (see vignettes 1, 2, 4 and 5 of Part 1 (Bridgett \& Polak, 2003, this issue) and vignette 7 below). This process can be achieved in meetings of those concerned by open discussion of the issues involved. Changes can be made relatively quickly when the discussion occurs within the crisis: maintaining tension in such meetings can facilitate resolution of conflict (Rosen, 1997). If left until later, reconstitution of a social system can

\section{Box 6 Long-term changes}

Clarify healthy roles and relationships Agree long-term support Anticipate future hazards Establish the relapse signature Improve local services in light of the crisis 


\section{Box 7 Community survival skills}

Self-care, housekeeping and cooking

Benefits and budgeting

Access to public transport

Finding and keeping a job

Not manifesting alarming behaviour

involve more prolonged work. The crisis resolution team can arrange for this help to be provided by others at follow-up.

The assessment in crisis will expose the significant circumstances, and the coping resources, of the individual in ways that enable subsequent risk management (Falloon \& Fadden, 1993: pp. 136-187). Part of this can usefully involve education: identifying the causes of illness relapse and agreeing indicators of relapse will establish a 'relapse signature'. This knowledge can usefully be shared with significant others (Birchwood \& Drury, 1995). A social prescription (Polak, 1967) might also include taking steps to improve local services, in the light of the lessons learnt from dealing with the crisis. Particular support might have been theoretically available to prevent the crisis, but might have been difficult to access in the event, perhaps because the resource had too low a profile. Suggestions by the crisis resolution team might make such help easier to obtain in the future.

Longer-term tasks involving others might include training in community survival skills (Polak et al, 1995) (Box 7).

\footnotetext{
Vignette 7

A middle-aged married woman with a long-term schizophrenic illness presents in relapse with florid delusions, precipitated by the stress of a family celebration and maintained by her fear that her husband will leave her.

When the couple is seen together it transpires that, in addition to being the breadwinner, the husband does virtually all the housework, shopping, laundry and cooking - when the wife once attempted to cook while he was out he returned to a smoke-filled home. The husband now makes it very clear that it would make a big difference to him if his wife could be helped to take on one or two domestic duties. The immediate intervention clarifies what is needed over the longer term to strengthen their relationship, as well as to improve the wife's self-esteem.
}

\section{Enabling early discharge from in-patient care}

All admissions to in-patient care can be considered for early discharge with help from a crisis resolution team. Assessment at the time of admission should

\section{Box 8 Enabling early discharge}

Consider early discharge at time of admission

Ensure collaboration between ward staff and the crisis resolution team

Review especially the referral crisis

Account for crisis of admission

Consider the influence of in-patient care

anticipate this (Box 8). A close working relationship between the team and the ward staff (Smyth, 2003), and all others involved, is important. Any of the crisis resolution and social systems considerations already mentioned might be relevant, but it is especially important to account for the failure in coping that necessitated the admission - the referral crisis. In addition to the social systems crises that preceded the referral crisis, the crisis of admission (Polak, 1967) must be taken into account: how has the admission affected the social systems to which the individual will return on discharge? It might also be relevant to take into account the influence of the in-patient care on the individual's coping behaviour, which is inevitably affected by social context. Any identified maladaptive responses should be addressed on an individual basis, and in relevant social systems meetings, by the promotion of healthy coping.

\section{The usefulness of predicting the future and auditing outcome}

It is recommended that crisis resolution teams regularly review outcomes (Box 9). On discharge from team follow-up, the crisis worker allocated to a case should identify the strengths and weaknesses in the available social support. This appraisal can be shown in the discharge summary as the social prognosis. A systematic review of this prognosis, for example at 6 or 12 months, in conjunction with an audit of actual outcome, would benefit future care planning by allowing improved prediction of, and control over, the relapse process (Birchwood \& Drury, 1995).

\section{Box 9 Prognosis and audit}

Identify strengths and weaknesses in social support

Include social prognosis in the discharge summary

Make a systematic review of prognosis

Audit outcome against prognosis

Feed back results for in-service training 
Vignette 8

A 59-year-old married woman is referred to the crisis resolution team by the accident and emergency department, with a 3-month history of anxiety and agitation over difficulty in swallowing, now presenting with acute thoughts of suicide and a refusal to return home. The team finds behind the referral crisis stress caused by accumulating financial difficulties: she is a businesswoman and entrepreneur. Most recently, her anxiety, which manifests itself with hypochondriacal concern about her throat, has been linked to a new business project into which she has put all the family assets. As her plans seem to be failing, she has worked longer hours, 7 days a week. Both she and her elderly husband are heavy alcohol drinkers.

Her physical state is reviewed and no abnormality discovered. Discussing her difficulties with her and her family enables them to understand what has happened: her physical symptoms are part of an adjustment disorder. She accepts anxiolytic and antidepressant medication, and discussions at home focus on the importance of re-establishing financial equilibrium. When the immediate crisis has been resolved she is referred on for follow-up by the community mental health team. It is recommended that she receive anxiety management training, coupled with further review of how her husband and she use alcohol. It is also thought important that they have further advice concerning their financial situation, including entitlement to state benefits, if her business plans continue to flounder. There is a clear risk of relapse if their circumstances remain dire, and their coping strategy using alcohol continues to be a factor.

Follow-up a year later reveals much general improvement in coping, with business ventures again established and financial support meanwhile obtained from entitled benefits. Anxiety management training has been helpful: the woman has discontinued her anxiolytic, and night sedation is no longer necessary. She does, however, continue to consult her family doctor concerning her throat and she admits to continuing daily use of alcohol above recommended limits. She is due to see her psychiatrist as an outpatient to discuss withdrawal from antidepressant medication.

\section{Conclusion}

The work done by a crisis resolution team is placed within the general field of crisis intervention (Rosen, 1997), but most such work does not involve acute psychiatric illness or mental health professionals. In his review of "problems with crisis "intervention"', Brimblecombe (2001) reflects on the difference between well-adjusted individuals for whom such help seemed originally intended (Caplan, 1964, 1974) and the type of patient likely to be referred for acute psychiatric in-patient care. He suggests that 'crisis intervention' does not lend itself to providing an alternative to in-patient care. 'Intensive home treatment' is his preferred term, implying the 'ward-on-wheels' approach, which certainly has advantages over standard in-patient care. What is overlooked, however, is that crisis intervention - and resolution - works not only with individuals, but also with the social systems to which the individuals relate.

Individuals presenting with florid episodes of mental illness have a varying ability to respond favourably to the approach described above, often with, but sometimes without, medication. However, it is when the social systems of the individual are taken into account that the crisis resolution approach comes into its own. As with intensive home treatment, the crisis intervention and resolution approach sees an individual's real-life setting as the preferred context for acute care, but with the awareness that enabling the relevant social systems of the individual to cope adaptively is a vital part of the work to be done.

This difference in emphasis highlights the variation that exists in the practical application of crisis intervention techniques for people with severe mental illness (Joy et al, 2001). Apart from the importance of current and future formal research (Burns \& Catty, 2002), it is evident that regular audit of current clinical practice needs to be in place. Innovation and evaluation should go hand in hand. There are many questions to ask. What proportion of clients have identifiable social systems crises that can be worked with? Which interventions are successful (Kawachi \& Berkman, 2001)? What training is required for teams working in this way? What are the differences in outcome achieved by adopting a social systems intervention approach?

Although the emphasis in this article is on the work of crisis resolution teams, accounting for the existence and influence of social systems is of general significance. Understanding human behaviour in terms of social systems provides an overall theoretical framework for community psychiatry, supporting for example the practical procedures involved in the care programme approach (Department of Health, 2000).

\section{References}

Belle, D. E. (1983) The impact of poverty on social networks and supports. Marriage and Family Review, 5, 89-103.

Birchwood, M. \& Drury, V. (1995) "Using the crisis". In Emergency Mental Health Services in the Community (eds M. Phelan, G. Strathdee \& G. Thornicroft), pp. 116-148. Cambridge: Cambridge University Press.

Bridgett, C. \& Polak, P. (2003) Social systems intervention and crisis resolution. Part 1: Assessment. Advances in Psychiatric Treatment, 9, 424-431. 
Brimblecombe, N. (2001) Community care and the development of intensive home treatment services. In Acute Mental Health Care in the Community: Intensive Home Treatment (ed. N. Brimblecombe), pp. 5-28. London: Whurr Books.

Burns, T. \& Catty, J. (2002) Mental health policy and evidence. Potentials and pitfalls. Psychiatric Bulletin, 26 324-327.

Caplan G (1964) Preventative Psychiatry. London: Tavistock. - (1974) Support Systems and Community Mental Health. New York: Behavioural Publications.

Department of Health (2000) Effective Care Coordination in Mental Health Services: Modernising the Care Programme Approach. A Policy Booklet. London: Stationery Office.

Falloon, I. R. H. \& Fadden, G. (1993) Integrated Mental Health Care: A Comprehensive, Community-Based Approach. Cambridge: Cambridge University Press.

Fish, L. (1971) Using social-systems techniques on a crisis unit. Hospital and Community Psychiatry, 22, 252-255.

Joy, C., Adams, C. \& Rice, K. (2001) Crisis intervention for people with severe mental illnesses. Cochrane Library, issue 4. Oxford: Update Software.

Kawachi, I. \& Berkman, L. F. (2001) Social ties and mental health. Journal of Urban Health: Bulletin of the New York Academy of Medicine, 78, 458-467.

Polak, P. R. (1967) The crisis of admission. Social Psychiatry, 2, 150-157.

- (1971) Social systems intervention. Archives of General Psychiatry, 25, 110-117.

- (1972) Techniques of social systems intervention. Current Psychiatric Therapies, 12, 185-193.

- Deever, S. \& Kirby, M. W. (1977) On treating the insane in sane places. Journal of Community Psychiatry, 5, 380387.

-, Kirby, M. \& Deitchman, W. S. (1995) Treating acutely psychotic patients in their private homes. In Alternatives to the Hospital for Acute Psychiatric Treatment (ed. R. Warner), pp. 49-64. Washington: American Psychiatric Press.

Rosen, A. (1997) Crisis management in the community. Medical Journal of Australia, 167, 633-638.

Smyth, M. G. (2003) Crisis resolution/home treatment and in-patient care. Psychiatric Bulletin, 27, 44-47.

\section{Multiple choice questions}

1 The first social systems meeting:

a should be delayed if possible

b may be more successful in a non-clinical setting

c needs a strict agenda

d can be particularly potent.

2 The following are recommended for social system meetings:

a face-to-face confrontation

$b$ interpretation

c focus on the 'here and now'

d exploration of non-verbal behaviour.

3 Early social systems interventions include:

a diagnosis

b coordinating involved support

c negotiating extra professional support

$\mathrm{d}$ improving understanding and communication.

4 Longer-term social systems interventions include:

a clarifying adaptive roles and relationships

b discharge from follow-up

c helping the patient to find and keep employment

d improving access to local services.

5 Achieving successful early discharge from inpatient care requires:

a successful medical treatment

b planning at time of admission

c the involvement of relevant social systems

$\mathrm{d}$ a meeting of the hospital managers.

MCQ answers

\begin{tabular}{|c|c|c|c|}
\hline & 2 & 3 & 4 \\
\hline $\mathrm{F}$ & a $\mathrm{T}$ & a F & a $\mathrm{T}$ \\
\hline $\mathrm{T}$ & $b F$ & $\mathrm{~b} T$ & $b F$ \\
\hline $\mathrm{F}$ & c $\mathrm{T}$ & c $\mathrm{T}$ & c $\mathrm{T}$ \\
\hline $\mathrm{T}$ & $\mathrm{d} T$ & $\mathrm{~d} T$ & $\mathrm{~d} T$ \\
\hline
\end{tabular}

